\title{
Toward a New Era of Research in Aerosol/Cloud/Climate Interactions at LLNL
}

C. Chuang, J. Dignon, K. Grant, P. Connell, D. Bergman, D. Rotman, D. Wright, R. McGraw and S. Schwartz

\section{September 27, 2000}




\section{DISCLAIMER}

This document was prepared as an account of work sponsored by an agency of the United States Government. Neither the United States Government nor the University of California nor any of their employees, makes any warranty, express or implied, or assumes any legal liability or responsibility for the accuracy, completeness, or usefulness of any information, apparatus, product, or process disclosed, or represents that its use would not infringe privately owned rights. Reference herein to any specific commercial product, process, or service by trade name, trademark, manufacturer, or otherwise, does not necessarily constitute or imply its endorsement, recommendation, or favoring by the United States Government or the University of California. The views and opinions of authors expressed herein do not necessarily state or reflect those of the United States Government or the University of California, and shall not be used for advertising or product endorsement purposes.

Work performed under the auspices of the U. S. Department of Energy by the University of California Lawrence Livermore National Laboratory under Contract W-7405-Eng-48.

This report has been reproduced directly from the best available copy.

Available to DOE and DOE contractors from the

Office of Scientific and Technical Information

P.O. Box 62, Oak Ridge, TN 37831

Prices available from (423) 576-8401

http://apollo.osti.gov/bridge/

Available to the public from the National Technical Information Service

U.S. Department of Commerce 5285 Port Royal Rd., Springfield, VA 22161 http://www.ntis.gov/

OR

Lawrence Livermore National Laboratory Technical Information Department's Digital Library http://www.llnl.gov/tid/Library.html 


\title{
Toward A New Era of Research in Aerosol/Cloud/Climate Interactions at LLNL
}

\author{
Catherine Chuang, Jane Dignon, Keith Grant \\ Peter Connell, Dan Bergman, Douglas Rotman \\ Atmospheric Science Division \\ Lawrence Livermore National Laboratory \\ Douglas Wright, Robert McGraw and Stephen Schwartz \\ Environmental Chemistry Division \\ Brookhaven National Laboratory
}

\begin{abstract}
One of the largest uncertainties in simulations of climate change over the industrial period is the impact of anthropogenic aerosols on the Earth's radiation budget. Much of this uncertainty arises from the limited capability for either precisely linking precursor gases to the formation and size distribution of the aerosols or quantitatively describing the existing levels of global aerosol loading. This project builds on our aerosol and chemistry expertise to address each of these uncertainties in a more quantitative fashion than is currently possible.

With the current LDRD support, we are in the process to implement an aerosol microphysics module into our global chemistry model to more fundamentally and completely describe the processes that determine the distribution of atmospheric aerosols. Using this new modeling capability, in conjunction with the most current version of NCAR climate model, we will examine the influence of these processes on aerosol direct and indirect climate forcing.
\end{abstract}

\section{Introduction}

Observations of global temperature records seem to show less warming than predictions of global warming brought on by increasing concentrations of $\mathrm{CO}_{2}$ and other greenhouse gases. One of the reasonable explanations for this apparent inconsistency is that the increasing concentrations of anthropogenic aerosols may be partially counteracting the effects of greenhouse gases.

Aerosols can scatter or absorb the solar radiation, directly change the planetary albedo. Aerosols, unlike $\mathrm{CO}_{2}$, may also have a significant indirect effect by serving as cloud condensation nuclei $(\mathrm{CCN})$. Increases in $\mathrm{CCN}$ can result in clouds with more but smaller droplets, enhancing the reflection of solar radiation. Aerosol direct and indirect effects are a strong function of the distributions of all aerosol types and the size distribution of the aerosol in question. However, the large spatial and temporal variabilities in the concentration, chemical characteristics, and size distribution of aerosols have made it difficult to assess the magnitude of aerosol effects on atmospheric radiation. These variabilities in aerosol characteristics as well as their effects on clouds are the leading sources of uncertainty in predicting future climate variation [see Figure 1].

Inventory studies have shown that the present-day anthropogenic emissions contribute more than half of fine particle mass primarily due to sulfate and carbonaceous aerosols derived from fossil fuel combustion and biomass burning [Andreae, 1995; Penner, 1995]. Parts of our earlier studies have been focused on developing an understanding of global sulfate and carbonaceous aerosol abundances and investigating their climate effects [Chuang et al., 1997; Penner et al., 1998; Chuang et al., 2000]. We have also modeled aerosol optical properties to account for changes in 
the refractive indices with relative humidity and dry aerosol composition [Grant et al., 1999]. Moreover, we have developed parameterizations of cloud response to aerosol abundance for use in global models to evaluate the importance of aerosol/cloud interactions on climate forcing [Ghan et al., 1993, 1995; Chuang and Penner, 1995]. Our research has been recognized as one of a few studies attempting to quantify the effects of anthropogenic aerosols on climate in the IPCC Third Assessment Report [IPCC, 2000a].

Our previous assessments of aerosol climate effects were based on a general circulation model (NCAR CCM1) fully coupled to a global tropospheric chemistry model (GRANTOUR). Both models, however, were developed more than a decade ago. The lack of advanced physics representation and techniques in our current coupled models limits us from further exploring the interrelationship between aerosol, cloud, and climate variation. Our objective is to move to a new era of aerosol/cloud/climate modeling at LLNL by coupling the most advanced chemistry and climate models and by incorporating an aerosol microphysics module. This modeling capability will enable us to identify and analyze the responsible processes in aerosol/cloud/climate interactions and therefore, to improve the level of scientific understanding for aerosol climate effects. This state-ofthe-art coupled models will also be used to address the relative importance of anthropogenic and natural emissions in the spatial pattern of aerosol climate forcing in order to assess the potential of human induced climate change.

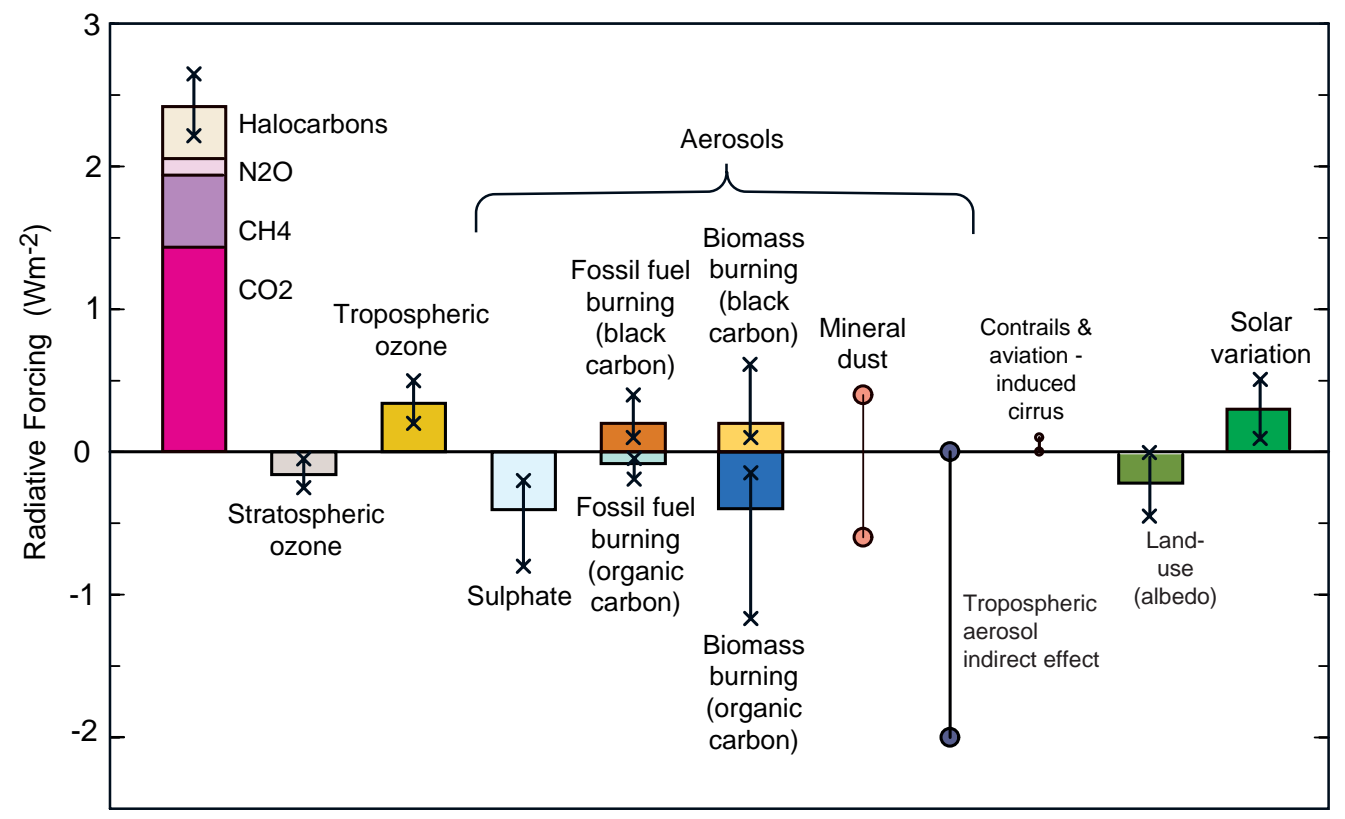

Figure 1. Global, annual-mean radiative forcings $\left(\mathrm{W} \mathrm{m}^{-2}\right)$ due to a number of agents from 1750 to present. The height of the rectangular bar denotes a 'mid-range' value while its absence denotes no best guess estimate is possible. The vertical line about the rectangular bar indicates an estimate of the uncertainty range [IPCC, 2000a]. 


\section{Model development}

The Atmospheric Sciences Division (ASD) has formulated a plan to enhance and expand our modeling expertise in aerosol/cloud/climate interactions. This plan builds on our experience and strength in this area and move into four new areas. First, we added a sulfur chemistry mechanism into the ASD global chemistry model, IMPACT (Integrated Massively Parallel Atmospheric Chemical Transport). Next, we developed an IMPACT aerosol version with a simplified sulfur chemistry together with other non-sulfate aerosol species for use in chemistry/climate coupling. Third, we will implement an aerosol microphysics module into the IMPACT aerosol version to include the important processes of aerosol dynamics. Finally, this chemistry-aerosol model will be linked to the most current version of NCAR CCM allowing detailed simulations of cloud cycles.

IMPACT, currently driven by the assimilated meteorological data, is an Eulerian global chemistry model that contains both a prognostic stratosphere and troposphere. Previously the model was applied to global ozone calculations. It is currently being expanded to include the chemistry necessary to simulate the sulfur cycle. IMPACT uses advanced techniques to treat the chemical and physical processes. These techniques include a chemistry equation solver which is capable of highly accurate solutions to both stiff and non-stiff sets of ordinary differential equations [Jacobson, 1995], an up-stream-biased monotonic grid point scheme for the advection [Lin and Rood, 1996], and an improved algorithm for dry deposition [Wang et al., 1997]. IMPACT also contains a more highly defined boundary layer than previous chemistry models and its spatial resolution allows for analysis of regional to global scale issues. IMPACT can run on a variety of platforms, including massively parallel computers. The ability to compute on parallel machines will greatly advance our throughout capabilities.

Livermore is unique to have a full chemistry model with interactive ozone and sulfur chemistry. However, a fast IMPACT version with sulfur chemistry together with other non-sulfate aerosol species is required for climate study in comparison the simulated climate response to aerosols with the 20-year period of satellite observations. Therefore, we are developing a special IMPACT aerosol version by not only adding species of organic carbon, black carbon, dust and sea salt but also using the monthly averages of $\mathrm{OH}, \mathrm{HO}_{2}$ and $\mathrm{O}_{3}$ in chemical reactions of sulfur compounds. This aerosol version is faster than the full chemistry version by a factor of 10 .

Since virtually all properties of atmospheric aerosols and clouds depend strongly on aerosol size distribution that are shaped by complicated nucleation, growth, and coagulation processes. These properties underlie the major role of aerosols in radiative forcing of climate. To better represent physical properties of aerosols, we adapted an aerosol microphysics module from the Brookhaven National Laboratory to model the spatial and temporal variations of aerosol size distribution. This module simulates the aerosol dynamics via the quadrature method of moments (QMOM) by tracking the moments of an aerosol size distribution in space and time [McGraw, 1997; Wright et al., 2000]. For a size distribution $f(r)$ of spherical particles of radius $r$ the $k^{\text {th }}$ radial moment is defined as

$$
\mu_{k}=\int_{0}^{\infty} r^{k} f(r) d r
$$

The QMOM employs only the low-order moments (six moments here, $k=0$ - 5) to model aerosol populations and properties. The QMOM offers significant advantages not only for efficiently and correctly incorporating aerosol processes in global models but also for its better representation of aerosol optical properties that are essential to assess the radiative forcing. 
After implementing the aerosol microphysics module into the IMPACT, we will couple the chemistry-aerosol model to the most current version of the community climate model (CCM) developed at NCAR (National Center for Atmospheric Research). This climate model contains prognostic cloud variables allowing more realistic simulations of aerosol effects on clouds. Moreover, it incorporates an optional slab mixed-layer ocean/thermodynamic sea-ice component able to predict the equilibrium response of climate to externally imposed changes, such as the concentrations of trace gases or the emission rates of various aerosol precursors. The structure of our proposed state-of-the-art coupled models is presented in Figure 2. In our coupled models, the IMPACT treats the global-scale transport, transformation, and removal of aerosols and aerosol precursors which sources are provided through emissions inventories, whereas the aerosol microphysics module traces the evolution of moments for each aerosol components. The chemistry/aerosol model provides aerosol characteristics to climate model for use in computing the radiative forcing, which in turn provides the meteorological fields that drive the chemistry/aerosol model. The most unique feature of our coupled models is the capability to simulate the variations of aerosol size distribution. This capability will allow us to address the aerosol radiative forcing on a much more solid foundation than previous studies that prescribed aerosol size distributions.

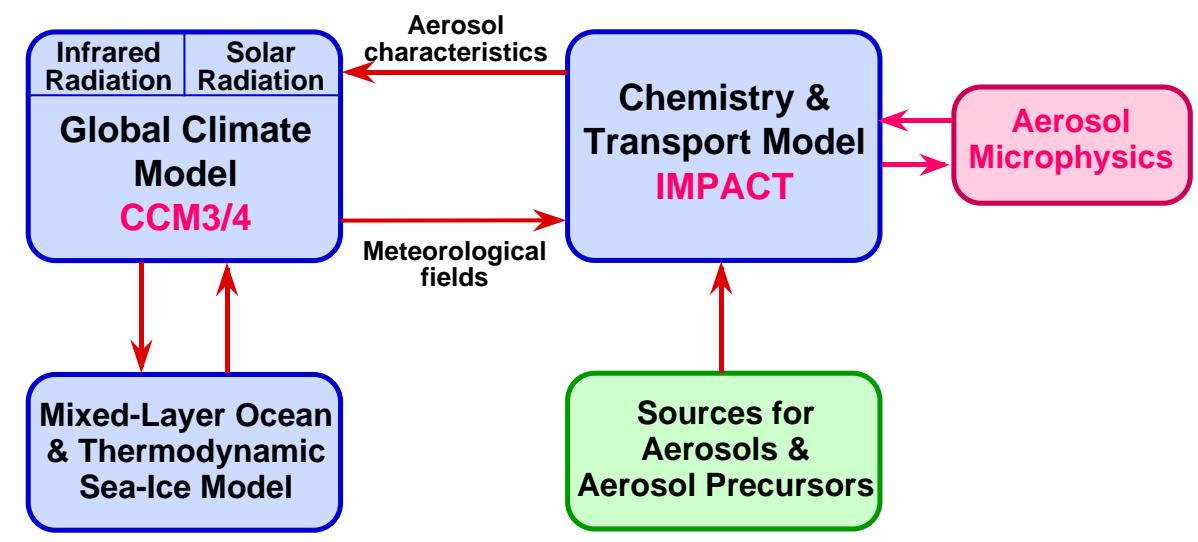

Figure 2. Structure of the proposed state-of-the-art coupled models.

\section{Progress to date}

\section{(a) Validation of full chemistry version with in-situ data}

In order to compare to the available data from field measurements, we ran the IMPACT full chemistry version for a time period overlapped with the NASA SONEX (SSAS Ozone and Nitrogen Oxide Experiment) project. SONEX project measures the trace species in the upper troposphere and lower stratosphere by flights of DC-8. Figure 3 shows the comparison of model simulated sulfate with those measured from flight number 6 (flight track from Shannon south to 32 $\mathrm{N})$ on October 20, 1997. Measurements are presented as 10-minute average and model is in onehour time step. Dashed line shows the mean of observations along the flight path, and the width of the shaded area represents one standard deviation above and below the mean. While the data exhibit large temporal and spatial variations, the model is able to capture their statistics average. Figure 3 indicates that the simulated concentrations compare well with observed means and are within observed standard deviations. Since IMPACT uses monthly averaged emissions databases and its resolution is large compared to small-scale variability, simulations are incapable of reproducing the high degree of variability along the flight path. 


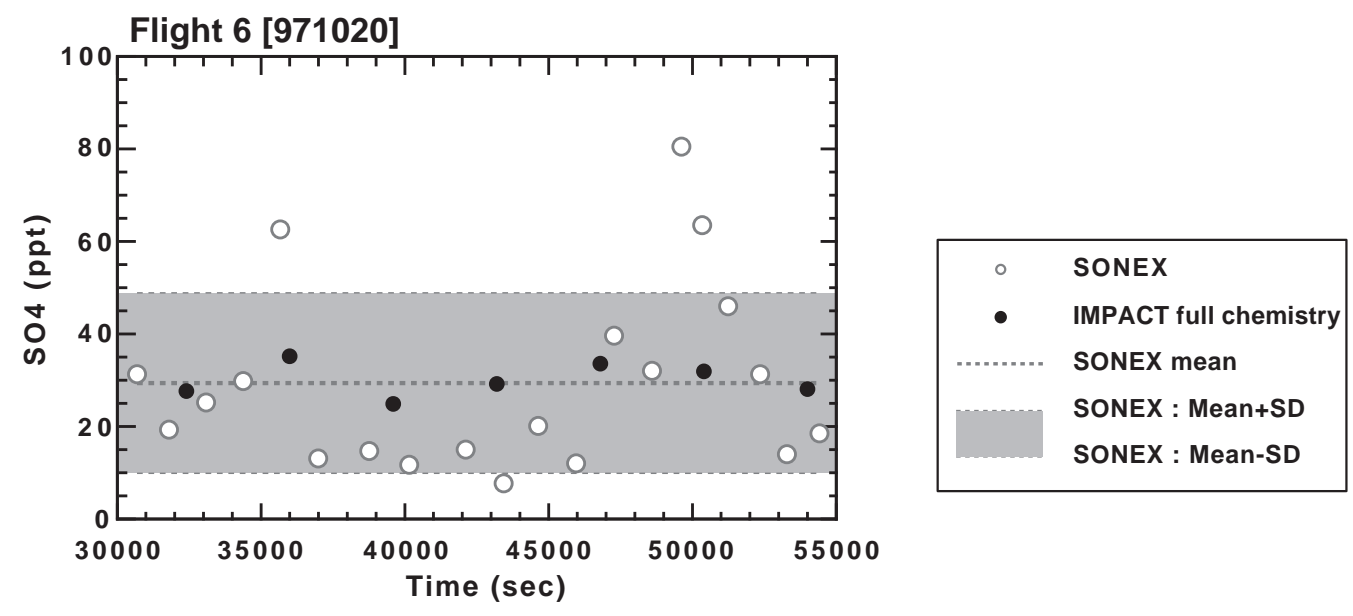

Figure 3. Comparison of the simulated $\mathrm{SO}_{4}{ }^{=}$by IMPACT full chemistry version with those measured from the NASA SONEX project.

\section{(b) Comparison of aerosol version with full chemistry version}

An efficient but accurate aerosol model is the first requirement to study the aerosol climatology where simulations over 10-40 years are necessary. In Figure 3 we demonstrate that the IMPACT full chemistry version can well represent the statistics of trace species, therefore, we validate the accuracy of the fast aerosol version with the full chemistry version. Figure 4 presents the concentrations of January $\mathrm{SO}_{2}, \mathrm{SO}_{4}=$, and $\mathrm{H}_{2} \mathrm{O}_{2}$ at sigma level 0.971 from the full chemistry (left panel) and from the fast aerosol version (right panel). The maximum regions are consistent and the general features are similar in these two versions. However, we notice that the concentration of $\mathrm{H}_{2} \mathrm{O}_{2}$ is significant lower in the aerosol version. This reduces the reaction of $\mathrm{SO}_{2}$ with $\mathrm{H}_{2} \mathrm{O}_{2}$ and results in a higher concentration of $\mathrm{SO}_{2}$ and a lower concentration of $\mathrm{SO}_{4}{ }^{2}$ in the aerosol version. The low $\mathrm{H}_{2} \mathrm{O}_{2}$ is mainly attributed to the use of the monthly averaged $\mathrm{HO}_{2}$ that fails to account for the significant diurnal variation of $\mathrm{HO}_{2}$ [see Figure 5], whereas the production of $\mathrm{H}_{2} \mathrm{O}_{2}$ is quadratically dependent on $\mathrm{HO}_{2}\left(\mathrm{HO}_{2}+\mathrm{HO}_{2} \longrightarrow \mathrm{H}_{2} \mathrm{O}_{2}+\mathrm{O}_{2}\right)$. Nevertheless, the $\mathrm{H}_{2} \mathrm{O}_{2}$ production can be improved by applying a correction factor as following.

$$
\begin{aligned}
\overline{\int d t \mathrm{Ph}\left(\mathrm{H}_{2} \mathrm{O}_{2}\right)} & =\overline{\int_{24 \mathrm{hrs}} d t k\left[\mathrm{HO}_{2}\right]^{2}} \\
& =k\left(\overline{\int_{24 \mathrm{hrs}} d t\left[\mathrm{HO}_{2}\right]}\right)^{2} * \overline{\int t t\left[\mathrm{HO}_{2}\right]^{2}} /\left(\overline{\int t\left[\mathrm{HO}_{2}\right]}\right)^{2} \\
& =k\left[\mathrm{HO}_{2}\right]^{2} \alpha
\end{aligned}
$$

where the overbar denotes the daily average, $\mathrm{k}$ is the rate constant for the production of $\mathrm{H}_{2} \mathrm{O}_{2}$ from $\mathrm{HO}_{2}$, and $\alpha$ is the correction factor derived from the species correlation. Figure 6 shows the magnitude of $\alpha$ calculated from LLNL 2-D box model [Kinnison and Connell, 1996]. A look-up table for $\alpha$ as a function of latitude, altitude and time will be incorporated into the aerosol version, and we will continue to validate the accuracy of the updated aerosol version with the full chemistry version. 
Full chemistry $\left[\mathrm{SO}_{2}\right.$ at $\left.\sigma=0.971\right]$

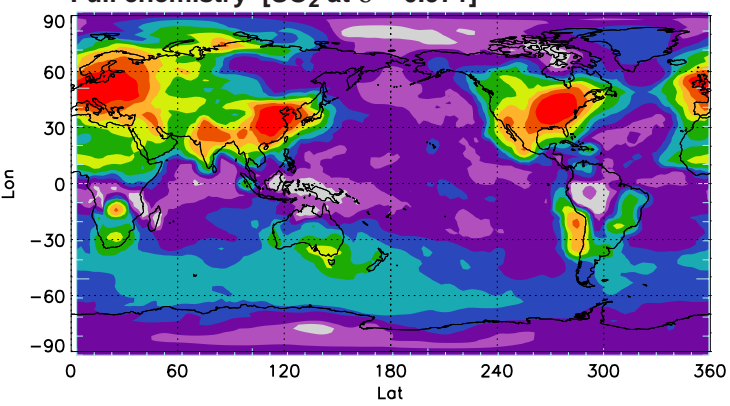

Full chemistry $\left[\mathrm{SO}_{4}\right.$ at $\left.\sigma=0.971\right]$

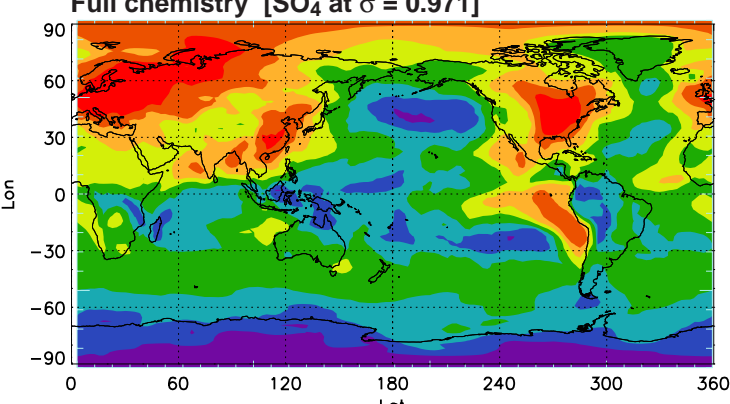

Full chemistry $\left[\mathrm{H}_{2} \mathrm{O}_{2}\right.$ at $\left.\sigma=0.971\right]$

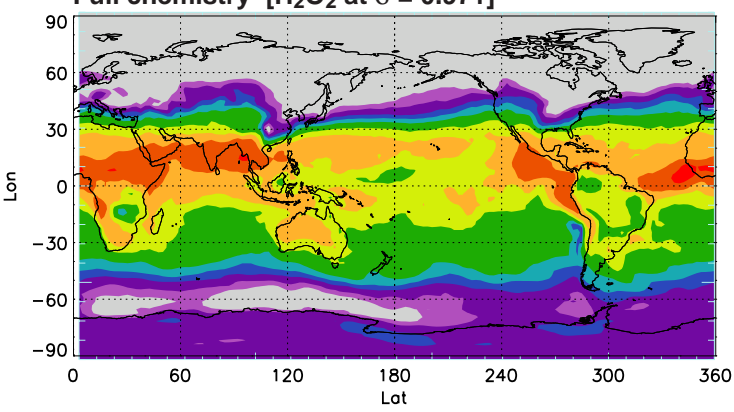

Aerosol version $\left[\mathrm{SO}_{2}\right.$ at $\left.\sigma=0.971\right]$
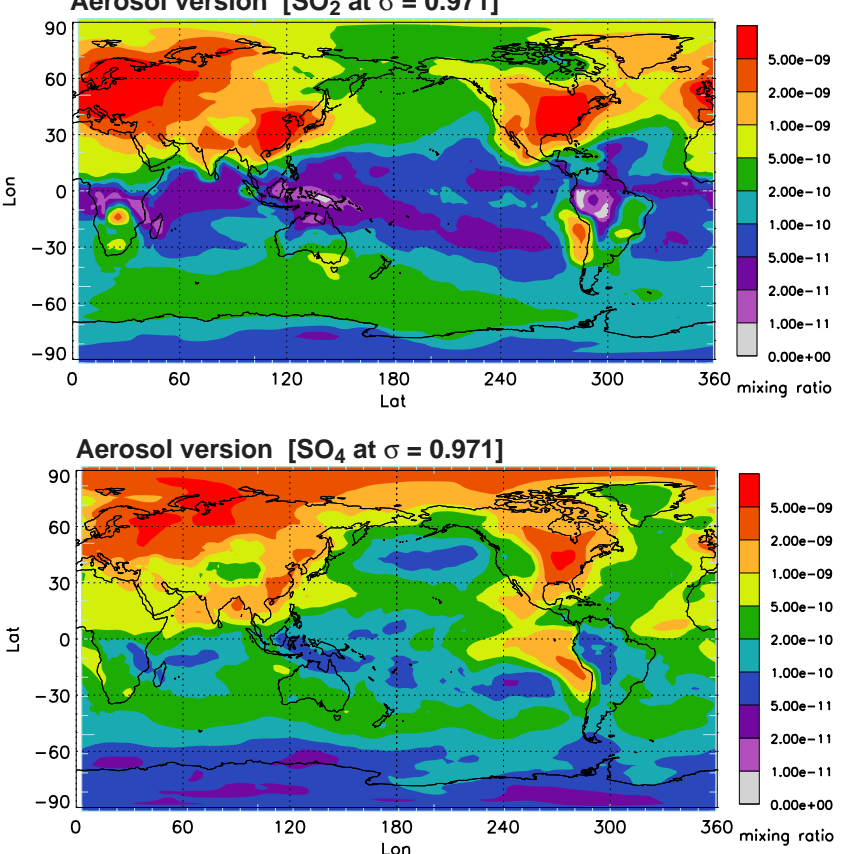

Aerosol version $\left[\mathrm{H}_{2} \mathrm{O}_{2}\right.$ at $\left.\sigma=0.971\right]$

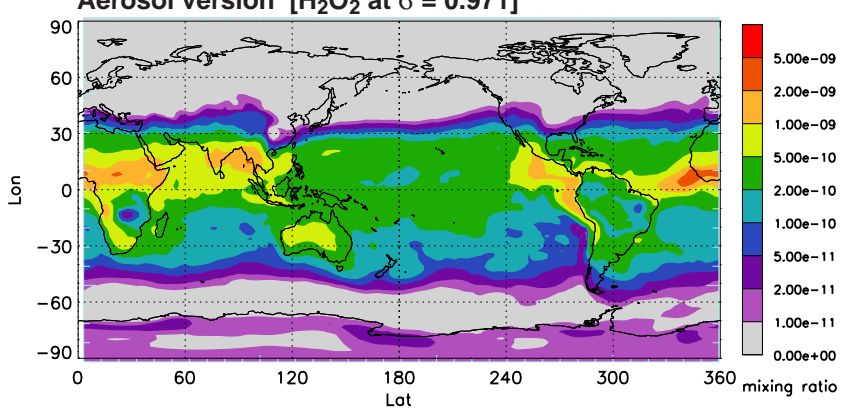

Figure 4. Comparison of the global distributions of January $\mathrm{SO}_{2}, \mathrm{SO}_{4}=$, and $\mathrm{H}_{2} \mathrm{O}_{2}$ at sigma level 0.971 from the fast aerosol version with those from the full chemistry version.

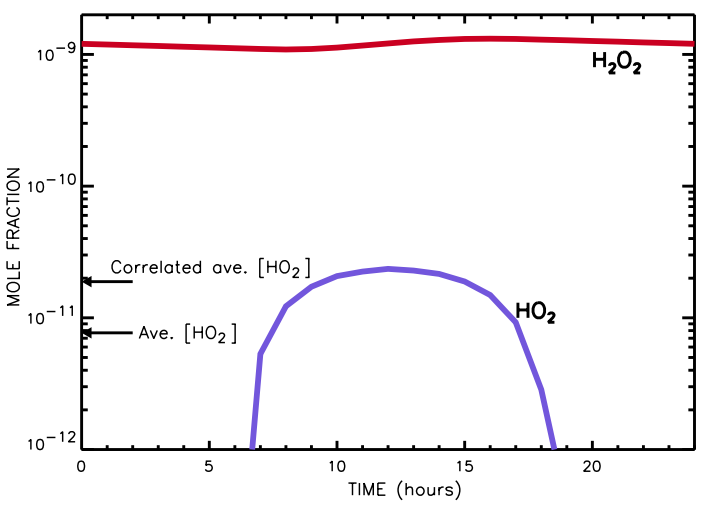

Figure 5. Diurnal behavior of $\mathrm{HO}_{2}$ and $\mathrm{H}_{2} \mathrm{O}_{2}$ (15 Mar, 2,5S, $6 \mathrm{~km}$ ) in LLNL 2-D box model.

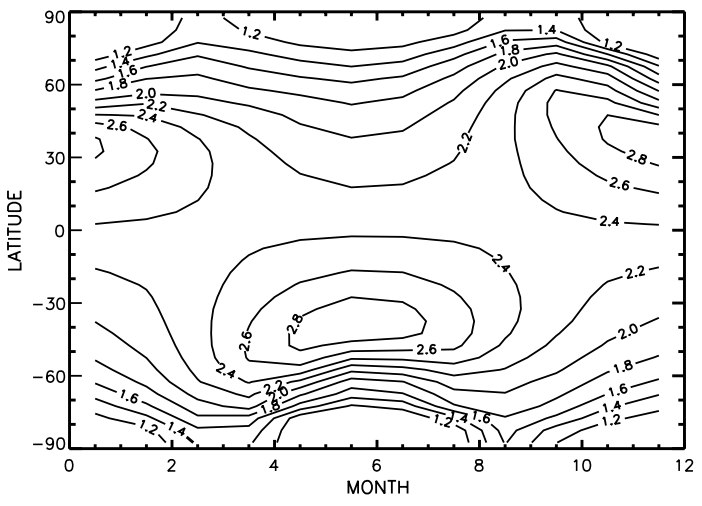

Figure 6. Magnitude of the correction factor $\alpha$ for $\mathrm{H}_{2} \mathrm{O}_{2}$ production at $6 \mathrm{~km}$. 


\section{(c) Validation of aerosol version with surface measurements}

We compared the model results from the aerosol version to surface measurements at a number of remote ocean sites that were part of a larger ocean network operated by a group at the University of Miami [Arimoto et al., 1995; Savoie et al., 1993]. Samples are collected by drawing air through large area filters at a flow rate of about $1 \mathrm{~m}^{3} \mathrm{~min}^{-1}$. Most sites are located at coastal sites on the climatological windward shore of islands or continental coastlines. The aerosol data are presented at monthly means of at least several years of data and in some cases almost 20 years of data. Comparisons of model-predicted seasonal surface concentrations of total non-seasalt sulfate to measurements at Bermuda, Fanning Island, and Palmer Station are shown in Figure 7. Most of the simulated concentrations are within one deviation of the mean of the measurements, but discrepancies do exist such as at the Palmer station. We will examine the ocean source of DMS and the mechanism to convert DMS to sulfate to look for the possible explanation.
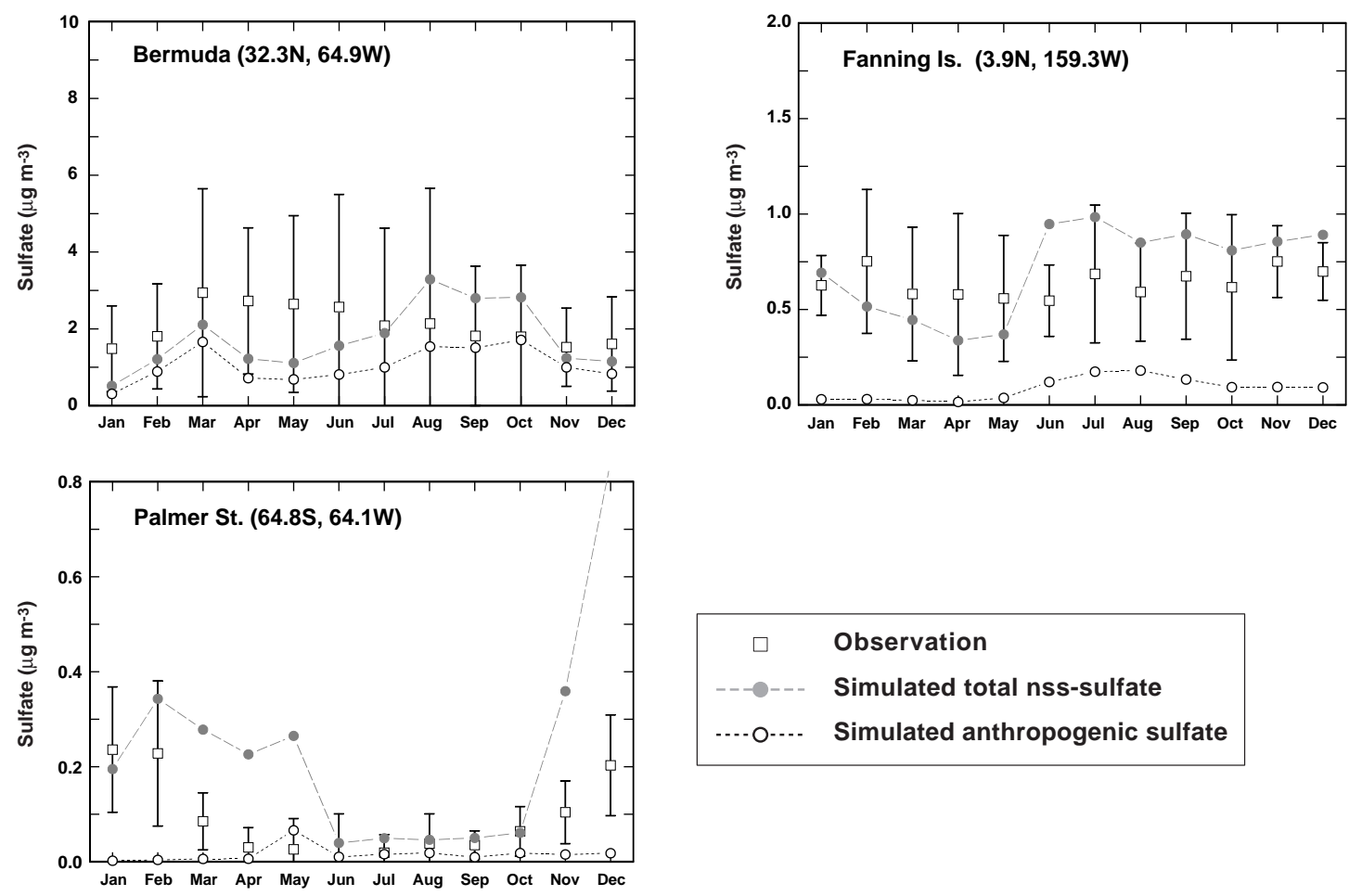

Figure 7. Modeled seasonal surface concentrations of nss-sulfate versus measurements at a series of Pacific and Atlantic locations. Error bars are one standard deviation above and below the mean of the measurements as compiled by Savoie and Prospero [private communication, 2000].

\section{(d) Evolution of aerosol size distribution moments}

The moments of each aerosol population evolve according to the general expression

$$
\frac{\mathrm{d} \mu_{k}}{\mathrm{~d} t}=\left[\frac{\mathrm{d} \mu_{k}}{\mathrm{~d} t}\right]_{\text {source }}+\left[\frac{\mathrm{d} \mu_{k}}{\mathrm{~d} t}\right]_{\text {cond }}+\left[\frac{\mathrm{d} \mu_{k}}{\mathrm{~d} t}\right]_{\text {coag }}+\left[\frac{\mathrm{d} \mu_{k}}{\mathrm{~d} t}\right]_{\text {cloud }}
$$

where the source term represents an influx of new aerosol particles into the aerosol population, either by nucleation from the vapor or by direct emission of particles. When operator-splitting is applied and the terms treated sequentially, the resulting equations are integrated numerically with a 
variable-time step scheme. We put this aerosol module in a box model to gain experience and understanding. Figure 8 illustrates the evolution of moments 0 and 3 in 16 hours for sulfate aerosols with an initial log-normal size distribution $\left(\mathrm{r}_{0}=0.01 \mu \mathrm{m}, \sigma=2, \mathrm{~N}=1000 \mathrm{~cm}^{-3}\right)$ under processes of nucleation, condensation, coagulation, and dry deposition. The concentrations of $\mathrm{SO}_{2}(\mathrm{~g})$ and $\mathrm{H}_{2} \mathrm{SO}_{4}(\mathrm{~g})$ are set to be $10^{-12} \mathrm{~mol} / \mathrm{cm}^{3}$ and $2 \times 10^{-16} \mathrm{~mol} / \mathrm{cm}^{3}$, respectively. The rate constant for $\mathrm{OH}$ oxidation of $\mathrm{SO}_{2}$ is $6 \times 10^{-7} \mathrm{~s}^{-1}$, and the concentration of sulfate produced in cloud is $10^{-12} \mathrm{~mol} / \mathrm{cm}^{3}$. Figure 8 demonstrates that nucleation process increases the aerosol number concentration, whereas coagulation and dry deposition decrease the total number. Although condensation will not change the total number concentration, it is the mainly process responsible for the increase of the total aerosol volume.

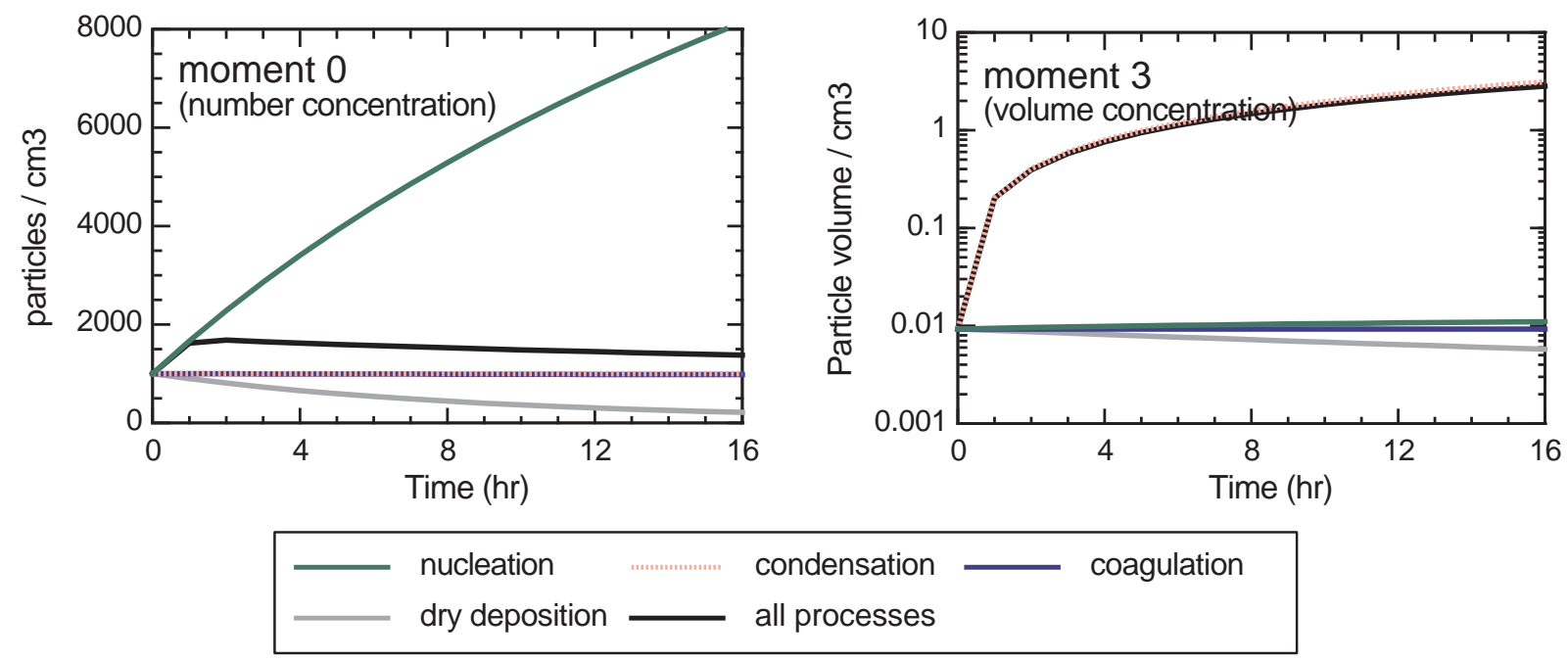

Figure 8. Evolution of aerosol size distribution moments under different dynamic processes.

\section{Future works}

Assessments of the climate impact by atmospheric aerosols rely on a precise description of aerosol optical properties and an accurate representation of temporal and spatial variations of aerosol distributions. With the fully coupled NCAR CCM/LLNL IMPACT-aerosol model, we will compare the simulated total aerosol optical depths and extinction profiles to those retrieved from satellite measurements such as NOAA Advanced Very High Resolution Radiometer, and EOS detectors like Moderate Resolution Imaging Spectroradiometer. We will validate whether our aerosol emissions inventories are correct and whether our treatments of transport and transformation are reasonable. We are interested in identifying the degree and conditions under which model and the observed aerosols demonstrate significant biases or departures in variability. In regions with significant aerosol extinction, we will characterize the scale of spatial covariance and the effects of such variability on radiative forcing.

It has been noticed that the patterns of climate change in response to anthropogenic aerosols alone and in response to increased levels of $\mathrm{CO}_{2}$ alone can be added linearly to obtain the approximate climate response to the combined forcing due to aerosols and $\mathrm{CO}_{2}$ together [Wigley, 1998]. Therefore, our second goal will be to compare the equilibrium pattern of climate response to the changes that have been detected during the 20-year period of satellite observations. The 
historical climate record reflects changes due to natural variability and responses to various anthropogenic and natural changes in atmospheric composition and surface conditions. We will examine how the pattern of surface temperature is distinct from the forcing pattern to explore the importance of atmospheric energy transport and the amplification by local feedback.

In order to characterize the future climate variations, our second task is to perform multiyear simulations along with the IPCC newly developed anthropogenic emissions scenarios to estimate the present and future projections of aerosol forcing up to 2100 [IPCC, 2000b]. We will not only calculate the climate forcing by both direct and indirect effects of aerosols but also examine the climate feedback associated with the presence of aerosols. In addition, we will investigate the net radiative fluxes by the changes of natural emissions associated with climate change. This work will provide us a more quantitative range for aerosol climate effects as compared to those from greenhouse gases.

\section{References}

Andreae, M. O., Climatic effects of changing atmospheric aerosol levels, in World Survey of Climatology, vol. 16, Future Climates of the World, edited by A. Henderson-Sellers, pp. 341392, Elsevier, New York, 1995.

Arimoto, R., R. A. Duce, B. J. Ray, W. G. Ellis, Jr., J. D. Cullen, and J. T. Merrill, Trace elements in the atmosphere over the North Atlantic, J. Geophys. Res., 100, 1199-1214, 1995.

Chuang, C. C., and J. E. Penner, Effects of anthropogenic sulfate on cloud drop nucleation and optical properties, Tellus, 47B, 566-577, 1995.

Chuang, C. C., J. E. Penner, K. E. Taylor, A. S. Grossman, and J. J. Walton, An assessment of the radiative effects of anthropogenic sulfate, J. Geophys. Res., 102, 3761-3778, 1997.

Chuang, C. C., J. E. Penner, J. M. Prospero, K. E. Grant, and G. H. Rau, Effects of anthropogenic aerosols on cloud susceptibility: A sensitivity study of radiative forcing to aerosol characteristics and global concentration, submitted to J. Geophys. Res., 2000.

Ghan, S. J., C. C. Chuang, and J. E. Penner, A parameterization of cloud droplet nucleation, I, Single aerosol type, Atmos. Res., 30, 197-221, 1993.

Ghan, S. J., C. C. Chuang, R. C. Easter, and J. E. Penner, A parameterization of cloud droplet nucleation, II, Multiple aerosol types, Atmos. Res., 36, 39-54, 1995.

Grant, K. E., C. C. Chuang, A. S. Grossman, and J. E. Penner, Modeling the spectral optical properties of ammonium sulfate and biomass burning aerosols: Parameterization of relative humidity effects and model results, Atmos. Environ., 33, 2603-2620, 1999.

Intergovernmental Panel on Climate Change (IPCC), Climate Change: The Scientific Basis, edited by J. T. Houghton and Y. Ding, draft, 2000a.

Intergovernmental Panel on Climate Change (IPCC), Special Report on Emissions Scenarios, draft, 2000a.

Jacobson, M. Z., 1995, Computation of global photochemistry with SMVGEAR II, Atmos. Environ., 29A ,2541-2546.

Kinnison, D. E., and P. S. Connell, Impact of high speed civil transports on stratospheric ozone: A 2-D model investigation, submitted to the International Colloquium for Impact of Aircraft Emissions Upon the Atmosphere, Paris, France, October 15-18, 1996 (UCRL-JC-126045).

Lin, S. J., and R. B. Rood, 1996, A fast flux form semi-Lagrangian transport scheme on the sphere, Mon. Wea. Rev., 124, 2046-2070.

McGraw R., Description of aerosol dynamics by the quadrature method of moments, Aerosol Sci. Technol. 27, 255-265, 1997. 
Penner, J. E., Carbonaceous aerosols influencing atmospheric radiation: black and organic carbon, in Aerosol Forcing of Climate, edited by R. J. Charlson and J. Heintzenberg, John Wiley and Sons, Chichester, 91-108, 1995.

Penner, J. E., C. C. Chuang, and K. E. Grant, Climate forcing by carbonaceous and sulfate aerosols, Clim. Dyn., 14, 839-851, 1998.

Savoie, D. L., J. M. Prospero, R. J. Larsen, Huang F., M. Izaguirre, Huang T., and T. H. Snowdon, Nitrogen and sulfur species in Antarctic aerosols at Mawson, Palmer Station, and Marsh (King George Island), J. Atmos. Chem., 17, 95-122, 1993.

Wigley, T. M. L, P. J. Jaumann, B. D. Santer, K. E. Taylor, Relative detectability of greenhouse-gas and aerosol climate change signals, Clim. Dyn., 14, 781-790, 1998.

Wang, Y. H., D. J. Jacob, and J. A. Logan, Global simulation of tropospheric $\mathrm{O}_{3}-\mathrm{NO}_{\mathrm{x}}$-hydrocarbon chemistry, 1. Model formulation, J. Geophys. Res., 103, 10,713-10,725, 1998.

Wright, D. L., R. McGraw, C. M. Benkovitz, and S. E. Schwartz, Six-moment representation of multiple aerosol populations in a sub-hemispheric chemical transformation model, Geophys. Res. Lett., 27, 967-970, 2000 